\title{
Antiviral effect of octyl gallate against influenza and other RNA viruses
}

\author{
HISASHI YAMASAKI $^{1}$, MISAO UOZAKI ${ }^{1}$, YUKIKO KATSUYAMA ${ }^{1}$, HIROTOSHI UTSUNOMIYA $^{2}$, \\ TSUTOMU ARAKAWA ${ }^{3}$, MASANORI HIGUCHI ${ }^{4,5}$, TOMIHIKO HIGUTI ${ }^{4}$ and A. HAJIME KOYAMA ${ }^{1}$ \\ ${ }^{1}$ Division of Virology, Department of Cellular and Molecular Medicine, ${ }^{2}$ Department of Pathology, Wakayama Medical \\ University Graduate School of Medicine, Wakayama 641-8509, Japan; ${ }^{3}$ Alliance Protein Laboratories, \\ Thousand Oaks, CA 91360, USA; ${ }^{4}$ Department of Molecular Cell Biology and Medicine, \\ Institute of Health Biosciences, The University of Tokushima Graduate School, \\ Tokushima 770-8505; ${ }^{5}$ MicroBiotech Inc., Tokushima 772-0051, Japan
}

Received November 15, 2006; Accepted January 2, 2007

\begin{abstract}
Octyl gallate inhibited the multiplication of several RNA viruses with widely different structure and replication strategies; i.e. vesicular stomatitis virus (VSV), influenza virus and poliovirus. In addition, octyl gallate showed virucidal activity against enveloped viruses at high concentrations. Characterization of the mode of action of octyl gallate against influenza virus infection revealed that the reagent delayed the onset of progeny virus formation. It did not, however, affect the rate of the formation, and the addition of the reagent at $2 \mathrm{~h}$ postinfection (p.i.), but not at $4 \mathrm{~h}$ p.i., almost completely abolished the formation of the progeny viruses, suggesting that the antiviral action of octyl gallate was not the result of a non-specific degeneration of the infected cells, but possibly the result of the inhibition at specific steps in the middle stage of the multiplication of influenza virus.
\end{abstract}

\section{Introduction}

Gallic acid (3,4,5-trihydroxybenzoic acid) is obtained by alkaline or acid hydrolysis of the tannins from nutgalls. It is one of the popular natural products of a variety of plants. Gallic acid and the alkyl derivatives are attracting attention due to their various pharmacological activities $(1,2)$. Some gallate derivatives have been well characterized and, because of their limited cytotoxity, are currently used as antioxidant food additives or as quasi drugs in Europe and Japan.

Correspondence to: Dr A. Hajime Koyama, Division of Virology, Department of Cellular and Molecular Medicine, Wakayama Medical University Graduate School of Medicine, 811-1 Kimiidera, Wakayama 641-8509, Japan

E-mail: koyama@wakayama-med.ac.jp

Key words: octyl gallate, influenza virus, RNA viruses, cell death, antiviral
Previously, we systematically characterized the antiviral activity of n-alkyl esters of gallic acid and found a relationship between the number of carbon atoms in the alkyl moiety of the molecules and their antiviral activity against herpes simplex virus type 1 (HSV-1) (3). However, regarding its activity against RNA viruses, we observed that octyl gallate, one of the alkyl gallates, affected the multiplication of the RNA virus, vesicular stomatitis virus (VSV), while others reported that methyl gallate was ineffective against RNA viruses, such as VSV and influenza virus (4), but was effective against HSV-1, consistent with our observation of octyl gallate. To solve this discrepancy concerning the antiviral activity of alkyl gallates against RNA viruses and to further explore the potential usefulness of octyl gallate as an antiviral drug against a wide range of viruses, we examined the effect of octyl gallate on the multiplication of a variety of RNA viruses with widely different structure and replication strategies.

\section{Materials and methods}

Cells and viruses. MDCK, HEp-2 and Vero cells were grown in Eagle's minimum essential medium (MEM) containing $10 \%$ newborn calf serum. Influenza virus A/Aichi $\left(\mathrm{H}_{3} \mathrm{~N}_{2}\right)$, poliovirus type 1 (Sabin strain), and VSV (New Jersey strain) were used throughout the experiments. The viruses were propagated in MDCK cells (for influenza virus) in MEM supplemented with $0.1 \%$ bovine serum albumin (BSA) and acetylated trypsin $(4 \mu \mathrm{g} / \mathrm{ml})$; or in Vero cells (for poliovirus and VSV) in MEM supplemented with $0.5 \%$ fetal bovine serum. These viruses were stored at $-80^{\circ} \mathrm{C}$ until use. The amount of each virus was measured by a plaque assay as described previously (5-7).

Virus yields in the presence of octyl gallate. The structure of octyl gallate is shown in Fig. 1. Octyl gallate was obtained from Tokyo Kasei. A stock solution $(2.0$ or $10.0 \mathrm{mg} / \mathrm{ml}$ ) was prepared by dissolving the reagent in dimethylsulfoxide, followed by filtration through a Millipore DIMEX membrane (pore size $0.22 \mu \mathrm{m}$ ) and was then stored in the dark at room temperature until use. 


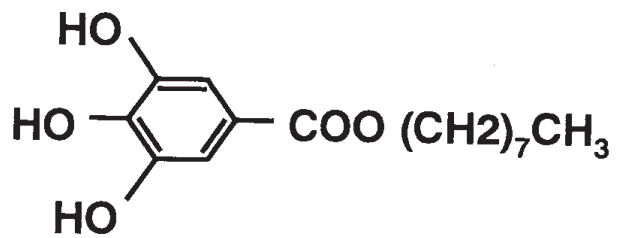

Figure 1. Structure of octyl gallate.

Monolayered cells in 35-mm dishes were infected with the virus at an indicated multiplicity of infection (MOI). The infected cells were further incubated at $37^{\circ} \mathrm{C}$ (for VSV and influenza virus) or $35.5^{\circ} \mathrm{C}$ (for poliovirus) for the indicated periods in serum-free MEM containing $0.1 \%$ BSA and the indicated concentrations of octyl gallate. For the experiments with influenza virus, acetylated trypsin $(4 \mu \mathrm{g} / \mathrm{ml})$ was also added to the medium for the activation of virus infectivity. At the end of infection, the culture medium was harvested and the amounts of total progeny virus in the medium were determined. For poliovirus, the progeny virus was harvested from both the culture media and the infected cells, which were lysed by two cycles of freezing and thawing.

Virucidal activity of octyl gallate. A series of virus preparations $\left[10^{5}\right.$ plaque-forming units (PFU) of the virus in $\left.900 \mu 1\right]$ in Dulbecco's phosphate-buffered saline without $\mathrm{Ca}^{++}$and $\mathrm{Mg}^{++}$ (PBS) containing $0.1 \%$ BSA (for influenza virus) or $1 \%$ calf serum (for poliovirus or VSV) received $100-\mu 1$ aliquots of octyl gallate solution at various concentrations and were incubated at room temperature for $20 \mathrm{~min}$. The viruses were diluted with ice-cold PBS containing $0.1 \%$ BSA or $1 \%$ calf serum, and the number of infectious viruses in the treated preparation was measured by a plaque assay.

Determination of cytopathic effects and cell death by infection with influenza virus. Monolayers of MDCK cells were mock-infected or infected with influenza virus at the indicated MOI. The infected cells were incubated in the serum-free MEM containing $0.1 \%$ BSA, acetylated trypsin $(4 \mu \mathrm{g} / \mathrm{ml})$ and the indicated concentrations of octyl gallate. The cytopathic effects (CPE) were determined by a microscopic observation of the cells; approximate amounts of rounded cells on monolayers were estimated under a phasecontrast microscope.

To determine the extent of cell death in the cultures, monolayered cells were trypsinized to obtain a single-cell suspension. After the addition of MEM containing 10\% calf serum to the suspension to neutralize the trypsin and to stabilize the cells, the number of living and dead cells was determined by a dye-exclusion method with trypan blue.

\section{Results and discussion}

Effect of octyl gallate on the multiplication of RNA viruses. To examine the effects of octyl gallate on RNA viruses in general, we tested three different types of viruses; VSV (Rhabdoviridae family), influenza virus (Orthomyxoviridae family) and poliovirus (Picornaviridae family). Both VSV and influenza virus are enveloped viruses carrying a negative-

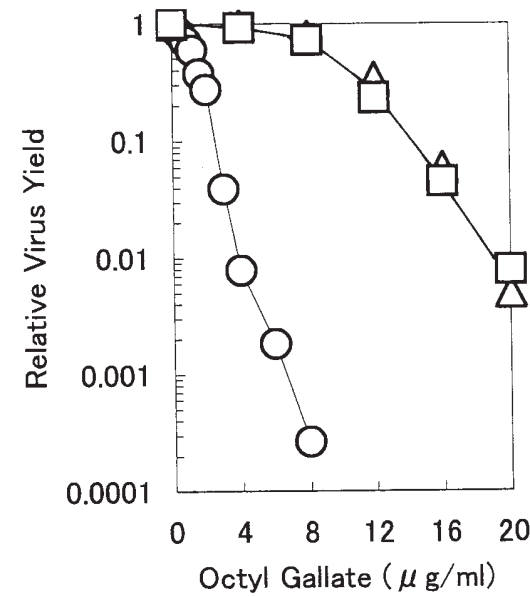

Figure 2. Effect of octyl gallate on the yields of RNA viruses. Confluent monolayers of HEp-2 (for VSV and poliovirus) or MDCK (for influenza virus) cells were infected with each of these three viruses at an MOI of 17 for VSV, 7 for influenza virus and 10 for poliovirus. The infected cells were incubated overnight in medium containing varying concentrations of octyl gallate at $37^{\circ} \mathrm{C}$ for influenza virus and VSV or at $35.5^{\circ} \mathrm{C}$ for poliovirus. At the end of infection, the amounts of infectious progeny viruses were determined and were normalized to the virus yield in the absence of the reagent. $\odot$, VSV; $\triangle$, influenza virus; $\square$, poliovirus.

stranded RNA as a genome, but the former can replicate sufficiently in the cell cytoplasm, while the latter absolutely requires the cell nucleus for virus multiplication (8). In contrast, poliovirus is a non-enveloped virus carrying a positive-stranded RNA as a genome which replicates in the cytoplasm of the infected cells (9).

Fig. 2 shows the effects of octyl gallate on the relative virus yields of these three viruses, when the infected cells were incubated in medium containing various concentrations of the reagent. The multiplication of VSV was highly sensitive to octyl gallate; the virus yield sharply decreased as the reagent concentration was increased to $8 \mu \mathrm{g} / \mathrm{ml}$. In the presence of $4 \mu \mathrm{g} / \mathrm{ml}$ of the reagent, the yield reached less than one hundredth of that in the absence of the reagent. This sensitivity of VSV was comparable to the reagent sensitivity of HSV-1, an enveloped double-stranded DNA virus (3). Although both influenza virus and poliovirus were less sensitive to the reagent than VSV, the multiplication of these two viruses was also affected by octyl gallate; the progeny virus yields of these two viruses showed a similar dosedependent decrease. A five-fold higher concentration $(20 \mu \mathrm{g} /$ $\mathrm{ml})$ was required for influenza virus and poliovirus than the concentration for VSV to achieve a 100-fold decrease in the yield (Fig. 2). These results clearly show that octyl gallate inhibits the multiplication of these RNA viruses which are widely different both in structure (i.e. enveloped or nonenveloped; positive- or negative-stranded genome RNA) and in their method of genome replication and transcription (i.e. in the nucleus or in the cytoplasm of the infected cells). These results are inconsistent with those of Kane et al (4) who previously reported that methyl ester of gallic acid effectively inhibits the multiplication of HSV-1, but not RNA viruses, such as VSV and influenza virus. We are uncertain whether this discrepancy concerning the antiviral effects of alkyl gallate on RNA viruses was due to the difference in chemical structure (octyl vs methyl) or in the assay conditions. 


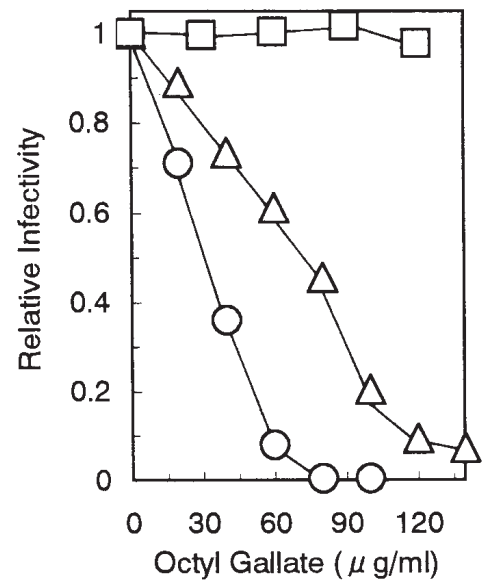

Figure 3. Direct virucidal effect of octyl gallate on RNA viruses. Aliquots of virus preparation were incubated at room temperature for $20 \mathrm{~min}$ in the presence of various concentrations of octyl gallate. The number of infectious viruses after the incubation was determined by a plaque method. $\odot$, VSV; $\triangle$, influenza virus; $\square$, poliovirus

In addition, it is worth noting that the antiviral activity of the reagent was apparently independent of the type of cells used; i.e. the multiplication of influenza virus was examined on MDCK cells (derived from canine kidney cells) while that of VSV or poliovirus was examined on HEp-2 cells (derived from human cervical carcinoma).

Virucidal effect of octyl gallate. Previously we found that octyl gallate directly inactivated HSV-1 at relatively high reagent concentrations. As shown in Fig. 3, the reagent was also able to inactivate VSV and influenza virus in a concentration-dependent manner, but not poliovirus at the tested range of concentrations. While both influenza virus and VSV are enveloped viruses, the observed virucidal effect of octyl gallate was clearly stronger on VSV than on influenza virus. HSV-1 was similar to VSV in its sensitivity to the reagent (3). Direct virucidal activity was also reported for other gallate derivatives, epigallocatechin-3-gallate and prodelphinidin B-2 3'-O-gallate (10-12), but the basis for the virucidal activity of the reagent remains unclear.

A time course study showed that the inactivation of the viruses by octyl gallate was rapid, occurring immediately after mixing the virus preparation with the reagent (data not shown). Previously we proposed a possible participation of antioxidant action of gallic moiety of the reagent in this direct inactivation of the viruses (3). However, when influenza virus was incubated systematically with a series of alkyl esters of gallic acids to a concentration of $120 \mu \mathrm{g} / \mathrm{ml}$, we found that, while ethyl, butyl and hexyl esters of gallic acid showed very weak virucidal activity, both decyl and lauryl esters showed much stronger activity than did octyl gallate. These results indicate that the gallic moiety alone is insufficient for the observed virucidal activity of these esters, and the alkyl group of the molecules plays an important role in this activity. Our previous proposal that the virucidal activity was caused by the antioxidant action of the reagent seems less likely. The alternative explanation is that the observed virucidal activity of the gallate esters with longer alkyl chains is due to the hydrophobic interaction between

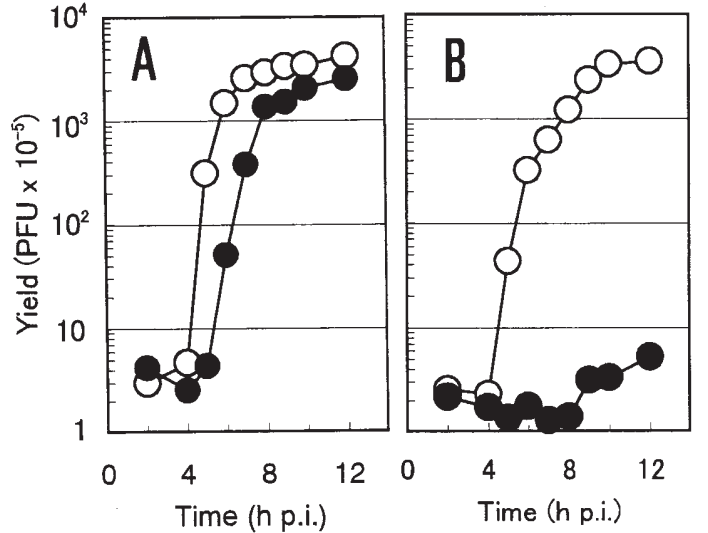

Figure 4. One-step growth curve of influenza virus in the presence or absence of octyl gallate. Confluent monolayers of MDCK cells were infected with influenza virus at an MOI of 13. The infected cells were incubated at $37^{\circ} \mathrm{C}$ in MEM containing $0.1 \%$ BSA and $4 \mu \mathrm{g} / \mathrm{ml}$ acetylated trypsin $(\odot)$ or in medium additionally containing $12 \mu \mathrm{g} / \mathrm{ml}(\mathrm{A})$ or $16 \mu \mathrm{g} / \mathrm{ml}$ (B) of octyl gallate $(\bullet)$. At the indicated time, the amounts of infectious progeny virus were determined.



Figure 5. Effect of the time of addition of octyl gallate on the virus yield. A group of confluent monolayers of MDCK cells were infected with influenza virus at an MOI of 14 and were incubated in MEM containing $0.1 \%$ BSA and acetylated trypsin $(4 \mu \mathrm{g} / \mathrm{ml})$. At various times after the infection, octyl gallate was added to the culture medium at a final concentration of $16 \mu \mathrm{g} / \mathrm{ml}$ and then the infected cells were further incubated in the presence of the reagent. The amount of progeny virus in each culture was determined at 14 h p.i.

the alkyl chains and virion components, as is evident from the chemical structure (Fig. 1). This explanation is also supported by the observation that octyl gallate was less effective when higher concentrations of BSA were present in the medium (data not shown). This was probably due to the effect of decreased free octyl gallate concentrations on the binding of the reagent to BSA by hydrophobic interaction between these two molecules.

Considering the potential applications of octyl gallate as an antiviral drug against influenza virus, we further characterized the mode of action of this reagent on the multiplication of influenza virus.

Multiplication of influenza virus in the presence of octyl gallate. Multiplication of influenza virus in the virus-infected cells proceeds as described below (8). Following the binding to the cell surface receptor, the virus particle is endocytosed, and viral nucleocapsids are released from the particle into the 
cytoplasm. Subsequently the expression of viral genes begins and the replication of the genome RNA and the formation of nucleocapsids take place in the infected cells. The assembly of nucleocapsids occurs beneath the plasma membrane, followed by the envelopment of nucleocapsids concomitantly with the budding at the plasma membrane and the formation of progeny virus.

Fig. 4A and B show one-step growth curves of influenza virus in the presence or absence of octyl gallate. In the absence of the reagent, the progeny infectious virus appeared after $4 \mathrm{~h}$ postinfection (p.i.), increased rapidly for the following $4 \mathrm{~h}$ and reached a plateau at $\sim 10 \mathrm{~h}$ p.i. However, in the presence of the reagent at $12 \mu \mathrm{g} / \mathrm{ml}$ (Fig. 4A), the onset of infectious progeny virus production was delayed for $\sim 1 \mathrm{~h}$, and the final virus yield was significantly less than the yield observed in the absence of the reagent, although the rate of the increase in the amount of progeny virus was not significantly affected by the reagent. At a higher reagent concentration $(16 \mu \mathrm{g} / \mathrm{ml})$, the onset of progeny virus production was further delayed for $4 \mathrm{~h}$ and the final yield under these conditions was highly suppressed (Fig. 4B). These one-step growth curves suggest that the reagent effectively slows down the progress of some steps in the early stage (i.e. before the envelopment of nucleocapsids at the plasma membrane) in the multiplication of influenza virus.

Previously we observed that the acceleration of cell death in the virus-infected cells was usually accompanied by a significant decrease in the progeny virus production $(13,14)$. In addition, the previous characterization of the antiherpetic action of octyl gallate (3) revealed that the reagent selectively accelerated both CPE and cell death in the virus-infected cells relative to those in the uninfected cells. Based on these observations we proposed that octyl gallate inhibits the virus multiplication as a result of acceleration of selective CPE and cell death in the virus-infected cells by the reagent (3). However, in contrast to HSV-1, influenza virus induced CPE in the infected MDCK cells so rapidly after infection that the acceleration of CPE by octyl gallate could not be detected in the influenza virus-infected cells. Consistent with these observations on $\mathrm{CPE}$, the induction of infected cell death was only slightly accelerated, if any, in the presence of the reagent at 12 or $16 \mu \mathrm{g} / \mathrm{ml}$ (data not shown).

Reagent-sensitive step in the virus multiplication. It has been reported by studies on the antiviral action of epigallocatechin-3-gallate and other polyphenolic compound catechins that the inhibition of influenza virus multiplication can occur at multiple stages in the virus replication cycle, such as during receptor binding, viral RNA synthesis and neuraminidase activity (12). To investigate the octyl gallate-sensitive step(s) in the multiplication of influenza virus, we added the reagent to the culture medium of the influenza virus-infected cells at various time post infection and harvested the progeny virus at the end of virus multiplication (14 h p.i.). As shown in Fig. 5, the reagent efficiently inhibited the formation of the progeny virus when added within a time period of $2 \mathrm{~h}$ p.i., but was much less effective at $4 \mathrm{~h}$ p.i.; there was essentially no effect by the addition of the reagent after $6 \mathrm{~h}$ p.i. These results indicate that initially, there is a critical reagent-sensitive step after the binding and entry step, since the addition of the reagent at $2 \mathrm{~h}$ p.i. effectively inhibited the virus multiplication, and second, there is no critical reagent-sensitive step in the late stage ( $6 \mathrm{~h}$ p.i. or later) of the virus multiplication, as addition of the reagent at this stage was ineffective. Judging from this critical period sensitive to octyl gallate, the reagent-sensitive steps in the virus multiplication are likely at transcription and/or at replication of the viral genome in the influenza virus-infected cells. If the observed in vitro virucidal effect of octyl gallate translates to an in vivo effect, then the binding of the reagent to certain cellular components or structures at this stage may be responsible for the inhibition of virus multiplication. We are now investigating the target of this possible binding in the infected cells.

\section{Acknowledgements}

The authors thank Ms. Kazuko Tsujimoto for her excellent technical and editorial assistance. This study was supported in part by a research grant from EMI (Epoch Medical International Inc.).

\section{References}

1. Cowan MM: Plant products as antimicrobial agents. Clin Microbiol Rev 12: 564-582, 1999.

2. Van der Heijden CA, Janssen PJCM and Strik JJTWA: Toxicology of gallates: A review and evaluation. Food Chem Toxicol 24: 1067-1070, 1986.

3. Uozaki M, Yamasaki H, Katsuyama Y, Higuchi M, Higuti T and Koyama AH: Antiviral effect of octyl gallate against DNA and RNA viruses. Antiviral Res (In press).

4. Kane CJM, Menna JH, Sung CC and Yeh YC: Methyl gallate, methyl-3,4,5-trihydroxy-benzoate, is a potent and highly specific inhibitor of herpes simplex virus in vitro. II. Antiviral activity of methyl gallate and its derivatives. Biosci Rep 8: 95$102,1988$.

5. Koyama AH: Induction of apoptotic DNA fragmentation by the infection of vesicular stomatitis virus. Virus Res 37: 285-290, 1995.

6. Koyama AH, Irie H, Ueno F, Ogawa M, Nomoto A and Adachi A: Suppression of apoptotic and necrotic cell death by poliovirus. J Gen Virol 82: 2965-2972, 2001.

7. Kurokawa M, Koyama AH, Yasuoka S and Adachi A: Influenza virus overcomes apoptosis by rapid multiplication. Int $\mathrm{J} \mathrm{Mol}$ Med 3: 527-530, 1999.

8. Lamb RA and Krug RM: Orthomyxoviridae: The viruses and their replication. In: Fields Virology. Fields BN, Knipe DM and Howley PM (eds). 4th edition, Lippincott-Raven, New York, pp1487-1530, 2001.

9. Racaniello VR: Picornaviridae: The viruses and their replication. In: Fields Virology. Fields BN, Knipe DM and Howley PM (eds). 4th edition, Lippincott-Raven, New York, pp685-722, 2001

10. Cheng HY, Lin CC and Lin TC: Antiviral properties of prodelphinidin B-2 3'-O-gallate from green tea leaf. Antiviral Chem Chemother 13: 223-229, 2002.

11. Cheng HY, Lin TC, Ishimaru K, Yang CM, Wang KC and Lin CC: In vitro antiviral activity of prodelphinidin B-2 3,3'-diO-gallate from Myrica rubra. Planta Med 69: 953-956, 2003.

12. Song JM, Lee KH and Seong BL: Antiviral effect of catechins in green tea on influenza virus. Antiviral Res 68: 66-74, 2005.

13. Koyama AH, Arakawa T and Adachi A: Acceleration of virusinduced apoptosis by tumor necrosis factor. FEBS Lett 426: 179-182, 1998.

14. Koyama AH, Fukumori T, Fujita M, Irie H and Adachi A: Physiological significance of apoptosis in animal virus infection. Microbes Infect 2: 1111-1117, 2000. 